
\title{
$\begin{array}{ll}\text { Research Square } & \begin{array}{l}\text { Preprints are preliminary reports that have not undergone peer review. } \\ \text { They should not be considered conclusive, used to inform clinical practice, } \\ \text { or referenced by the media as validated information. }\end{array}\end{array}$
}

\section{The importance of cardiorespiratory fitness in obesity-related disease: a cross sectional-analysis}

Angelo Sabag ( $\nabla$ a.sabag@westernsydney.edu.au )

Western Sydney University https://orcid.org/0000-0002-0195-7029

Shelley E. Keating

University of Queensland - Saint Lucia Campus: The University of Queensland

Kimberley L. Way

The University of Sydney

Rachelle N. Sultana

The University of Sydney

\section{Sean M. Lanting}

The University of Newcastle

Stephen M. Twigg

The University of Sydney

Nathan A. Johnson

The University of Sydney

\section{Research article}

Keywords: Cardiorespiratory Fitness, Obesity, Fatty Liver, Diabetes, Insulin Resistance, Exercise

Posted Date: October 29th, 2020

DOI: https://doi.org/10.21203/rs.3.rs-97543/v1

License: (ㅇ (i) This work is licensed under a Creative Commons Attribution 4.0 International License. Read Full License

Version of Record: A version of this preprint was published at BMC Sports Science, Medicine and Rehabilitation on April 16th, 2021. See the published version at https://doi.org/10.1186/s13102-021-00261-9. 


\section{Abstract}

Background: Exercise-induced improvements in cardiorespiratory fitness (CRF) often coincide with improvements in insulin sensitivity and intrahepatic lipid content $(\mathrm{IHL})$. The aim of this study was to examine the association between CRF, IHL, and insulin resistance in inactive adults with obesity and with or without type 2 diabetes, via cross-sectional design.

Methods: CRF was determined via a graded exercise test. IHL was assessed via proton magnetic resonance spectroscopy $\left({ }^{1} \mathrm{H}-\mathrm{MRS}\right)$ and insulin resistance was assessed via homeostatic model of insulin resistance (HOMA-IR). Participants were stratified into CRF quartiles and analysis of variance was employed to determine significant differences in IHL\%, HOMA-IR and cardiometabolic outcomes between CRF quartiles.

Results: Seventy-two adults ( $46 \%$ male) with a mean age of $49 \pm 10$ years, $\mathrm{HL}$ of $8.37 \pm 6.90 \%$, and CRF of $21.52 \pm 3.77 \mathrm{~mL} / \mathrm{kg} / \mathrm{min}$ participated in this study. CRF was inversely associated with IHL $(r=-0.28, p=0.019)$ and HOMA-IR $(r=-0.40, p<0.001)$. Participants with the lowest CRF had significantly higher IHL $\%$ and HOMA-IR than those with the highest CRF $(+5.31 \%, p=0.021 ;+2.50, p=0.001$, respectively). Participants with the lowest CRF also had significantly greater cardiovascular and inflammatory abnormalities than those with the highest CRF.

Conclusion: CRF was inversely associated with IHL and HOMA-IR and participants with the highest levels of CRF had significantly lower cardiometabolic risk than those with the lowest levels of fitness. Improving CRF should remain a key therapeutic target for the management of obesity-related disease.

\section{Background:}

Obesity plays a significant role in the development of many chronic diseases such as hypertension, coronary heart disease, numerous cancers, and type 2 diabetes (T2D) [1]. Whilst the relationship between obesity and increased cardiometabolic risk is well established [2], the location of adipose tissue, particularly in and/or around the liver, heart, muscles, and pancreas, also known as ectopic fat, is significantly more predictive of adverse health outcomes such as hypertension and hyperglycaemia [3]. Metabolic dysfunction-associated fatty liver disease (MAFLD), characterised by excessive intrahepatic lipid concentration (IHL), is strongly linked with insulin resistance and is highly prevalent in individuals with T2D [4]. As T2D and MAFLD share a similar underlying pathological process, they often present alongside other disorders such as obesity, dyslipidaemia, and hypertension [5]. A known strategy for managing these risk factors is increased physical activity [6, 7], which importantly leads to improved cardiorespiratory fitness (CRF) [8]. However, individuals with T2D and/or MAFLD reportedly experience disease-related aerobic impairments, which contribute to, or are further affected by, mitochondrial dysfunction, cardiac dysfunction, insulin resistance, impaired lipid-handling, and diastolic dysfunction - which may manifest as low CRF [9, 10].

Low CRF is a well-established risk factor for all-cause morbidity and mortality [11] and increases an individual's risk for developing T2D [12, 13]. While many lifestyle interventions such as diet modulation rely on weight loss for cardiometabolic improvement [14], studies have shown that individuals who engage in structured exercise can improve CRF and insulin sensitivity as well as reduce IHL without significant change in body weight [15-17]. Furthermore, a recent study showed that low CRF was strongly and independently associated with MAFLD prevalence [18], however, these findings are yet to be confirmed using gold-standard measurement of $\mathrm{IHL}$ and maximal exercise tests to determine CRF.

Decoupling CRF from physical activity-related improvements has proven difficult due to the interrelated nature of the two measures [12, 13]. It could therefore be assumed that individuals who have higher physical activity and CRF levels also partake in other healthy behaviours, which provide further protection from a variety of obesity-related complications [19]. Importantly, it is becoming increasingly accepted that both modifiable (such as physical activity levels) and nonmodifiable factors (such as gene-specific variations) contribute to variations in CRF [20,21], with the relative genetic contribution to $\mathrm{CRF}$ reported to be $\sim 50 \%$ $[20,22]$. Therefore, it is important to explore the association between CRF and cardiometabolic risk in adults with similar levels of self-reported physical activity in order to decouple physical activity from CRF and better assess CRF-related benefits independently. There are limited studies which have investigated the relationship between CRF and insulin resistance in adults with and without T2D, and even fewer studies assessing the relationship between CRF and IHL as quantified by gold-standard proton magnetic spectroscopy ( $\left.{ }^{1} \mathrm{H}-\mathrm{MRS}\right)$. Therefore, the aim of this cross-sectional study, was to determine whether CRF was associated with $\mathrm{IHL}$, insulin resistance, and other cardiometabolic outcomes in inactive adults with obesity, and with or without T2D. A secondary aim was to compare cardiometabolic and CRF differences between adults with T2D to those without T2D.

\section{Methods:}

\section{Participants}

The participants of this study were recruited via electronic bulletins, clinical databases, and media advertisements between June 2011 and April 2019 . Eligible volunteers were between the ages of $18-65$ years, had a BMI $\geq 30.0 \mathrm{~kg} / \mathrm{m}^{2}$, self-reported being physically inactive (exercising $<3$ days/week) and/or not currently meeting physical activity guidelines. All participants were screened by a medical practitioner prior to enrolment and were excluded if there was evidence of an unstable cardiac condition, uncontrolled hypertension, or uncontrolled blood glucose. The analysis included 72 volunteers from two larger intervention trials (ACTRN12614001220651 and ACTRN12614000723684). The study conformed to the ethical guidelines of the 1975 Declaration of Helsinki and the procedures were approved by The University of Sydney Human Research Ethics Committee. Eligible participants were screened via telephone interview and those whom met the inclusion criteria and provided written informed consent, were enrolled in the study and underwent assessments at The University of Sydney (NSW, Australia).

\section{Anthropometry and Blood Pressure Assessment}


The height of the participants was measured via stadiometer (SECA model 220 Telescopic Height Rod, Hamburg, Germany). Participant body weight was measured (Tanita BC-418 Body Composition Analyzer; Tanita Corporation, Tokyo, Japan) to the nearest $0.1 \mathrm{~kg}$ and BMI (kg/m²) was calculated. Waste circumference (WC) was measured thrice horizontally, between the inferior margin of the ribs and the superior border of the iliac crest after expiration but before inspiration. After 10-15 min of quiet sitting, systolic (SBP) and diastolic blood pressure (DBP) were measured manually on each arm with a sphygmomanometer, and the average of three measures was recorded from the arm which produced the highest SBP and DBP readings.

\section{Biochemical Parameters}

Venous blood was collected after an overnight fast (> 10 hours) for the purpose of determining fasting blood glucose (FBG), insulin, high-sensitivity C-reactive protein (CRP), total cholesterol (TC), triglycerides (TG), high-density lipoprotein cholesterol (HDL), low-density lipoprotein cholesterol (LDL), alanine aminotransferase (ALT), and aspartate aminotransferase (AST). All biochemical and lipid assessments were completed by a private accredited laboratory. Insulin resistance was assessed via the homeostatic model of insulin resistance (HOMA-IR) [23].

\section{Proton Magnetic Resonance Spectroscopy ( $\left.{ }^{1} \mathrm{H}-\mathrm{MRS}\right)$}

IHL\% was measured by proton magnetic resonance spectroscopy ( ${ }^{1} \mathrm{H}-\mathrm{MRS}$ ) using a Phillips Intera 1.5 Telsa Achieva MRI system (Philips Medical Systems, Best, Netherlands). Spectral data were post-processed by an assessor (NAJ), who was blinded to participant details, using a magnetic resonance user interface software (jMRUI, version 5.2; www.jmrui.eu) [24, 25]. IHL\% $\geq 5.5 \%$ was considered consistent with the presence of metabolic dysfunction-associated fatty liver disease (MAFLD) [26-28]. The IHL\% quantification methodology employed in this study is comprehensively detailed elsewhere [17].

\section{Cardiorespiratory fitness}

CRF was measured by a graded maximal exercise test on an electronically-braked cycle ergometer (Lode Corival, Netherlands) under the supervision of an accredited exercise physiologist. All tests incorporated a three-min warm up at $35 \mathrm{~W}$ and $65 \mathrm{~W}$ for women and men, respectively, and workloads were incrementally adjusted by $25 \mathrm{~W}$ every $150 \mathrm{sec}$ until volitional fatigue. Heart rate, blood pressure, and ratings of perceived exertion (RPE) were obtained at each stage of exercise, with RPE measured using the Borg scale [29]. The test was terminated when the pedalling rate fell below 50 revolutions per min despite encouragement, or volitional fatigue. Peak work capacity $\left(\mathrm{W}_{\text {peak }}\right)$ was measured [30] and peak oxygen consumption $\left(\mathrm{VO}_{2}\right.$ Peak $)$ estimated as described previously [31]. CRF was assessed within one-week of IHL assessment.

\section{Statistical Analysis}

Data were analysed using Statistical Package for the Social Sciences (SPSS version 24.0; IMB Corp., Armonk, NY, USA). All data are reported as the mean values \pm standard deviation from the mean (SD) unless otherwise stated. Independent $t$ tests were used to compare differences in $\mathrm{VO}_{2 \text { peak }}$ and other biochemical and anthropometric measures between individuals with and without T2D. Homogeneity of variances was assessed via Levene's test for equality of variance and $\mathrm{X}^{2}$ for categorical data. Abnormally distributed primary outcome measures were transformed via natural logarithm prior to between-group comparisons. Pearson coefficients $(r)$ were used for correlations between continuous variables, and where one of the variables was dichotomous categorical data and the other was continuous. Associations between two categorical variables were assessed by $\mathrm{X}^{2}$ test for independence, whereby the phi coefficient determined the strength of the association. Male and female participants were divided into CRF quartiles, respectively, and analysis of variance was employed to determine significant differences in cardiometabolic outcomes between CRF quartiles.

\section{Results:}

\section{Participants}

Participant characteristics are summarised in Table 1 . A total of 72 ( $46 \%$ male) volunteers participated in this study. The mean age was $49 \pm 10$ years, BMI $34.69 \pm 4.87 \mathrm{~kg} / \mathrm{m}^{2}$, waist circumference $108.55 \pm 14.43 \mathrm{~cm}$, IHL was $8.37 \pm 6.90 \%$, and $\mathrm{VO}_{2 \text { peak }}$ was $21.52 \pm 3.77 \mathrm{ml} / \mathrm{kg} / \mathrm{min}$. The prevalence of $\mathrm{MAFLD}$ was $43 \%, 65 \%$, and $54 \%$ in normal glucose tolerance, T2D, and in all participants, respectively. Participants with T2D had significantly higher WC, IHL \%, HOMA-IR, FBG, ALT, TC, HDL, LDL, and FFA than those without T2D ( $p<0.05$ for all). There were no differences in other variables between participants with or without T2D. 
Table 1

Participant characteristics.

\begin{tabular}{|c|c|c|c|c|}
\hline & Normal Glucose Tolerance $(n=37)$ & Type 2 Diabetes $(n=35)$ & Total $(n=72)$ & $\mathbf{p}$ \\
\hline \multicolumn{5}{|c|}{ Demographics and anthropometry } \\
\hline Gender (M/F) & $13 / 24$ & $20 / 15$ & $33 / 39$ & 0.61 \\
\hline MAFLD $(\mathrm{Y} / \mathrm{N})$ & $16 / 21$ & $23 / 12$ & $39 / 33$ & 0.056 \\
\hline Age (years) & $44.84(10.23)$ & $53.97(7.85)$ & $49.28(10.18)$ & $<0.001$ \\
\hline Waist Circumference (cm) & $101.21(12.30)$ & $116.30(12.43)$ & $108.55(14.43)$ & $<0.001$ \\
\hline $\mathrm{BMI}\left(\mathrm{kg} / \mathrm{m}^{2}\right)$ & $33.62(4.52)$ & $35.81(5.04)$ & 34.69 (4.87) & 0.056 \\
\hline IHL (\%) & $6.59(5.93)$ & $10.25(7.43)$ & $8.37(6.90)$ & 0.008 \\
\hline $\mathrm{SBP}(\mathrm{mmHg})$ & $122.92(14.41)$ & $129.41(16.85)$ & $126.07(15.87)$ & 0.083 \\
\hline $\mathrm{DBP}(\mathrm{mmHg})$ & $79.30(6.99)$ & $80.16(9.28)$ & $79.71(8.14)$ & 0.658 \\
\hline \multicolumn{5}{|l|}{ Biochemistry } \\
\hline AST (U/L) & $22.32(9.17)$ & $29.06(21.05)$ & $25.60(16.32)$ & 0.080 \\
\hline $\operatorname{ALT}(U / L)$ & $22.95(10.13)$ & $35.17(23.10)$ & $28.89(18.59)$ & 0.005 \\
\hline CRP (mg/L) & $4.65(4.71)$ & $4.11(4.73)$ & $4.39(4.70)$ & 0.628 \\
\hline FBG (mmol/L) & $4.28(0.61)$ & $8.21(3.00)$ & $6.19(2.90)$ & $<0.001$ \\
\hline${ }^{\wedge}$ Insulin (mU/L) & $10.22(5.96)$ & $12.17(6.63)$ & $11.08(6.29)$ & 0.212 \\
\hline${ }^{\wedge} \mathrm{HOMA-IR}$ & $2.00(1.34)$ & $4.43(2.61)$ & $3.07(2.33)$ & $<0.001$ \\
\hline \multicolumn{5}{|l|}{ Lipids } \\
\hline Triglyceride (mmol/L) & $1.49(0.86)$ & $1.66(0.67)$ & $1.57(0.78)$ & 0.368 \\
\hline Total Cholesterol (mmol/L) & $5.59(1.25)$ & $4.43(0.80)$ & $5.03(1.20)$ & $<0.001$ \\
\hline $\mathrm{HDL}(\mathrm{mmol} / \mathrm{L})$ & $1.40(0.32)$ & $1.15(0.26)$ & $1.28(0.32)$ & 0.001 \\
\hline LDL (mmol/L) & $3.53(0.95)$ & $2.47(0.75)$ & $3.02(1.01)$ & $<0.001$ \\
\hline FFA (umol/L) & $389.67(162.24)$ & $508.71(198.24)$ & 447.54 (189.09) & 0.007 \\
\hline \multicolumn{5}{|l|}{ Cardiorespiratory Fitness } \\
\hline $\mathrm{VO}_{2 \text { peak }}(\mathrm{mL} / \mathrm{kg} / \mathrm{min})$ & $22.24(3.90)$ & $20.75(3.51)$ & $21.52(3.77)$ & 0.094 \\
\hline \multicolumn{5}{|c|}{$\begin{array}{l}\text { M: male; F: female; MAFLD: metabolic dysfunction-associated fatty liver disease; Y: yes; N: no; BMI: body mass index; IHL: intrahepatic lipid; SBP: systolic } \\
\text { blood pressure; DBP: diastolic blood pressure; AST: aspartate aminotransferase; ALT: alanine aminotransferase; CRP: high-sensitivity C-reactive protein; } \\
\text { FBG: fasting blood glucose; HOMA-IR: homeostatic model assessment of insulin resistance; HDL: high-density lipoprotein cholesterol; LDL: low-density } \\
\text { lipoprotein cholesterol; FFA: free fatty acid; VO } \mathrm{O}_{2} \text { : Peak oxygen consumption. ^HOMA-IR and insulin measures reported for } 37 \text { participants with normal } \\
\text { glucose tolerance and } 29 \text { participants with T2D as } 6 \text { participants with T2D were undergoing exogenous }\end{array}$} \\
\hline
\end{tabular}

\section{CRF and cardiometabolic outcomes}

Participants characteristics stratified by CRF are summarised in Table 2. Participants with the lowest CRF had significantly higher IHL\% and HOMA-IR than those in the highest CRF $(+5.31 \%, p=0.021,+2.50, p=0.001$, respectively) (Fig. 1). When compared to participants with the highest CRF, those with the lowest CRF had significantly higher BMI $\left(+7.54 \mathrm{~kg} / \mathrm{m}^{2}, \mathrm{p}<0.001\right)$, WC $(+18.65 \mathrm{~cm}, \mathrm{p}<0.001), \mathrm{CRP}(+3.80 \mathrm{mg} / \mathrm{L}, \mathrm{p}=0.012) \mathrm{glucose}(+2.06 \mathrm{mmol} / \mathrm{L}, \mathrm{p}=0.034)$, insulin ( $+5.57 \mathrm{mU} / \mathrm{L}, \mathrm{p}=0.008)$, FFA ( $+153.34 \mathrm{umol} / \mathrm{L}, \mathrm{p}=0.015)$, and SBP $(+16.57 \mathrm{mmHg}, \mathrm{p}=0.001)$. When compared to participants with CRF scores within the interquartile range, those with the lowest CRF had significantly higher BMI $\left(+7.54 \mathrm{~kg} / \mathrm{m}^{2}, p<0.001\right), W C(+18.65 \mathrm{~cm}, \mathrm{p}<0.001), \mathrm{CRP}(+3.93 \mathrm{mg} / \mathrm{L}, \mathrm{p}=$ $0.003)$ and SBP $(+10.89 \mathrm{mmHg}, \mathrm{p}=0.014)$. 
Table 2

Participant characteristics when stratified by cardiorespiratory fitness

\begin{tabular}{|c|c|c|c|c|}
\hline & Lowest Fitness $(n=18)$ & IQR $(n=36)$ & Highest Fitness ( $n=18)$ & Between group p \\
\hline \multicolumn{5}{|c|}{ Demographics and anthropometry } \\
\hline Gender (M/F) & $8 / 10$ & $17 / 19$ & $8 / 10$ & 0.974 \\
\hline Type 2 Diabetes $(\mathrm{Y} / \mathrm{N})$ & $11 / 7$ & $18 / 18$ & $6 / 12$ & 0.250 \\
\hline MAFLD $(\mathrm{Y} / \mathrm{N})$ & $15 / 3$ & $16 / 20$ & $8 / 10$ & $0.015 *+$ \\
\hline Age (years) & $54.56(9.94)$ & $47.33(9.48)$ & $47.89(10.47)$ & 0.037 *十 \\
\hline Waist Circumference (cm) & $119.03(15.38)$ & $107.39(12.64)$ & $100.38(10.70)$ & $<0.001$ *† \\
\hline $\mathrm{BMI}\left(\mathrm{kg} / \mathrm{m}^{2}\right)$ & 39.81 (4.29) & 33.34 (3.55) & 32.27 (4.12) & $<0.001$ *† \\
\hline IHL (\%) & $11.40(6.25)$ & $8.00(7.48)$ & $6.08(5.40)$ & $0.033^{*}$ \\
\hline $\mathrm{SBP}(\mathrm{mmHg})$ & $135.66(20.17)$ & $124.77(13.08)$ & $119.09(11.86)$ & $0.004^{*}+$ \\
\hline $\mathrm{DBP}(\mathrm{mmHg})$ & $83.21(11.33)$ & $78.60(6.58)$ & $78.44(6.46)$ & $0.107^{\star}$ \\
\hline \multicolumn{5}{|l|}{ Biochemistry } \\
\hline AST (U/L) & $30.39(22.57)$ & $25.78(16.16)$ & $20.44(3.62)$ & 0.189 \\
\hline $\operatorname{ALT}(U / L)$ & $34.72(22.72)$ & $29.22(18.81)$ & $22.39(10.82)$ & $0.136^{*}$ \\
\hline CRP (mg/L) & $7.30(6.72)$ & $3.38(3.41)$ & $3.51(3.30)$ & $0.008^{*}+$ \\
\hline FBG (mmol/L) & $7.14(3.16)$ & $6.26(3.14)$ & $5.01(1.59)$ & $0.101^{\star}$ \\
\hline${ }^{\wedge}$ Insulin (mU/L) & $14.29(7.79)$ & $10.68(6.16)$ & $8.72(3.37)$ & $0.026^{\star}$ \\
\hline${ }^{\wedge} \mathrm{HOMA-IR}$ & $4.56(2.89)$ & $2.82(2.06)$ & $2.08(1.44)$ & $0.004^{*}+$ \\
\hline \multicolumn{5}{|l|}{ Lipids } \\
\hline Triglyceride (mmol/L) & $1.61(0.75)$ & $1.57(0.73)$ & $1.54(0.91)$ & 0.973 \\
\hline Total Cholesterol (mmol/L) & $4.93(1.34)$ & $4.93(1.24)$ & $5.30(0.95)$ & 0.527 \\
\hline $\mathrm{HDL}(\mathrm{mmol} / \mathrm{L})$ & $1.30(0.30)$ & $1.22(0.34)$ & $1.38(0.29)$ & 0.223 \\
\hline LDL (mmol/L) & $2.88(1.10)$ & $2.96(1.03)$ & $3.27(0.87)$ & 0.464 \\
\hline FFA (umol/L) & $531.83(196.93)$ & $439.92(188.65)$ & 378.49 (156.79) & $0.047^{\star}$ \\
\hline \multicolumn{5}{|c|}{$\begin{array}{l}\text { IQR: interquartile range; M: male; F: female; MAFLD: metabolic dysfunction-associated fatty liver disease; Y: yes; N: no; BMI: body mass index; IHL: } \\
\text { intrahepatic lipid; SBP: systolic blood pressure; DBP: diastolic blood pressure; AST: aspartate aminotransferase; ALT: alanine aminotransferase; CRP: high } \\
\text { sensitivity C-reactive protein; FBG: fasting blood glucose; HOMA-IR: homeostatic model assessment of insulin resistance; HDL: high-density lipoprotein } \\
\text { cholesterol; LDL: low-density lipoprotein cholesterol; FFA: free fatty acid; VO }{ }_{2} \text { : Peak oxygen consumption. ^HOMA-IR and insulin measures reported for } 37 \\
\text { participants with normal glucose tolerance and } 29 \text { participants with } \mathrm{T}_{2} \mathrm{D} \text { as } 6 \text { participants with T2D were undergoing exogenous insulin therapy. *: } \\
\text { significant difference between lowest and highest fitness; }+ \text { : significant difference between lowest fitness and IQR. }\end{array}$} \\
\hline
\end{tabular}

\section{Bivariate correlations}

The associations between CRF, demographic, anthropometric, and cardiometabolic variables are summarised in Table 3 . CRF was significantly associated with IHL\% ( $r=-0.276)$, HOMA-IR $(r=-0.396)$, BMI $(r=-0.514)$, WC $(r=-0.383)$, ALT $(r=-0.233)$, FFA $(r=-0.313)$, CRP $(r=-0.344)$ FBG $(r=-0.261)$, insulin $(r=$ $-0.350)$, and SBP $(r=-0.287)(p<0.05$ for all). 
Table 3

Correlations of graded exercise test measured cardiorespiratory fitness, demographic, cardiometabolic, and antr

\begin{tabular}{lllllllllllll}
1 & 2 & 3 & 4 & 5 & 6 & 7 & 8 & 9 & 10 & 11 & 12 & 13 \\
\hline
\end{tabular}

\section{IHL\%}

(1)

HOMA- $\quad 0.393^{* \star}$

IR (2)

Age (3) $\quad 0.111 \quad 0.17$

Gender $\quad-0.071 \quad-0.272^{*} \quad 0.036$

(4)

\begin{tabular}{llllll} 
T2D (5) & $0.267^{*}$ & $0.524 \dagger$ & $0.452 \dagger$ & -0.221 & \\
\hline MAFLD & $0.735 \dagger$ & $0.448 \dagger$ & 0.215 & -0.175 & 0.225
\end{tabular}

(6)

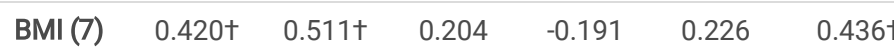

\begin{tabular}{|c|c|c|}
\hline WC (8) & 0.497 & \\
\hline
\end{tabular}

$\begin{array}{lllllllll}\text { AST (9) } & 0.432 \dagger & 0.069 & 0.072 & -0.154 & 0.208 & 0.338^{* *} & 0.299^{*} & 0.387^{*}\end{array}$

$\begin{array}{llllllllll}\text { ALT } & 0.587 \dagger & 0.276^{*} & 0.168 & -0.169 & 0.331^{* *} & 0.432 \dagger & 0.385^{* *} & 0.500 \dagger & 0.900 \dagger \\ (10) & & & & & & & & \end{array}$

\begin{tabular}{llllllllllll} 
TRIG & 0.064 & $0.270^{*}$ & $0.264^{*}$ & -0.103 & 0.108 & $0.285^{*}$ & -0.082 & 0.104 & 0.137 & 0.152 & \\
$(11)$ & & & & & & & & & & \\
\hline TC (12) & -0.101 & $-0.382^{* *}$ & -0.002 & $0.410 \dagger$ & $-0.485+$ & -0.104 & $-0.240^{*}$ & $-0.427 \dagger$ & -0.027 & -0.099 & 0.186 \\
\hline
\end{tabular}

\begin{tabular}{|c|c|c|c|c|c|c|c|c|c|c|c|c|c|c|}
\hline $\begin{array}{l}\text { HDL } \\
\text { (13) }\end{array}$ & -0.111 & -0.234 & -0.031 & $0.508 \dagger$ & $-0.398^{\star \star}$ & -0.2 & -0.161 & $-0.436+$ & -0.23 & $-0.292^{*}$ & -0.200 & $0.615 t$ & & \\
\hline $\begin{array}{l}\text { LDL } \\
\text { (14) }\end{array}$ & -0.167 & $-0.489+$ & -0.038 & $0.365^{\star \star}$ & $-0.530+$ & -0.161 & -0.23 & $-0.414 \dagger$ & -0.066 & -0.134 & 0.001 & $0.950 \dagger$ & $0.520 \dagger$ & \\
\hline $\begin{array}{l}\text { FFA } \\
\text { (15) }\end{array}$ & $0.371^{\star *}$ & $0.256^{*}$ & 0.193 & 0.154 & $0.317^{\star \star}$ & $0.368^{* *}$ & 0.15 & 0.201 & $0.332^{\star \star}$ & $0.337^{\star \star}$ & 0.202 & 0.102 & 0.085 & 0.00 \\
\hline $\begin{array}{l}\text { CRP } \\
\text { (16) }\end{array}$ & 0.132 & 0.027 & -0.024 & $0.249 *$ & -0.058 & 0.130 & $0.322^{\star \star}$ & 0.089 & 0.197 & 0.183 & 0.022 & 0.005 & 0.067 & -0.02 \\
\hline $\begin{array}{l}\text { Glucose } \\
\text { (17) }\end{array}$ & $0.295^{\star}$ & $0.657 \dagger$ & $0.259^{*}$ & -0.227 & $0.681 \dagger$ & $0.242^{*}$ & 0.196 & $0.476 t$ & 0.204 & $0.296^{*}$ & 0.134 & $-0.306^{* *}$ & $-.277^{*}$ & $-0.4 \varepsilon$ \\
\hline $\begin{array}{l}\text { Insulin } \\
\text { (18) }\end{array}$ & $0.388^{\star *}$ & $0.803+$ & -0.126 & -0.217 & 0.156 & $0.382^{\star *}$ & $0.504 t$ & $0.459 \dagger$ & 0.022 & 0.214 & 0.217 & -0.234 & -0.185 & -0.31 \\
\hline $\begin{array}{l}\text { SBP } \\
(19)\end{array}$ & 0.208 & $0.388^{\star \star}$ & $0.339^{\star \star}$ & $-0.280^{*}$ & 0.206 & $0.411 \dagger$ & $0.360^{\star \star}$ & $0.544 t$ & $0.315^{\star \star}$ & $0.357^{\star \star}$ & $0.325^{\star \star}$ & -0.075 & $-0.238^{*}$ & $-0.0 \subseteq$ \\
\hline $\begin{array}{l}\text { DBP } \\
(20)\end{array}$ & 0.227 & $0.382^{\star *}$ & 0.221 & -0.192 & 0.053 & $0.320^{\star \star}$ & $0.292^{*}$ & $0.365^{\star \star}$ & -0.049 & -0.009 & $0.263^{*}$ & 0.049 & 0.132 & -0.0 ᄃ \\
\hline CRF & $-0.276^{*}$ & $-0.396^{\star *}$ & -0.158 & -0.087 & -0.199 & -0.193 & $-0.514 \dagger$ & $-0.383^{\star *}$ & -0.192 & $-0.233^{\star}$ & -0.024 & 0.076 & 0.03 & 0.10 \\
\hline
\end{tabular}

$(21)$

$* p<0.05 ; * * p<0.01 ;+0.001$

Data presented are the correlation coefficient $(r)$. intrahepatic lipid; T2D: type 2 diabetes; MAFLD: metabolic dysfunction-associated fatty liver disease; BMI: $k$ aminotransferase; ALT: alanine aminotransferase; TRIG: triglyceride; TC: Total Cholesterol; HDL: high-density lipoprotein cholesterol; LDL: low-density lipoprol reactive protein; SBP: systolic blood pressure; DBP: diastolic blood pressure; CRF: cardiorespiratory fitness.

Differences in IHL\% between CRF quartiles. IHL\%, intrahepatic lipid \%; HOMA-IR, homeostatic model of insulin resistance. Brackets indicate significant differe

\section{Discussion:}

This study is one of the first to show significant relationships between key cardiometabolic risk factors, such as gold-standard ${ }^{1} \mathrm{H}$-MRS quantified IHL\%, and CRF in individuals with and without T2D. The findings of this study showed that the prevalence of MAFLD amongst participants with T2D was 65\%, which coincide with previous reports [32]. Further analyses showed that even relatively small variations in CRF were associated with increased IHL\% and insulin resistance, which were significantly higher in individuals with the lowest CRF than those with highest CRF. Similarly, individuals with the highest CRF had lower cardiometabolic and inflammatory abnormalities than those with the lowest CRF. The findings of this study suggest that improving CRF should remain a key therapeutic target for the management of obesity-related disease such as comorbid T2D and MAFLD.

Low CRF is a well-accepted independent risk factor for morbidity and mortality [11], and improving CRF is being increasingly adopted as a therapeutic target for improving cardiometabolic health in individuals with or at risk of obesity-related disease [12, 13]. Currently, few studies have assessed the association 
between CRF and direct measures of IHL or MAFLD. For example, the results of the Young Finns study involving 463 participants showed that CRF was strongly, inversely, and independently associated with ultrasound-quantified fatty liver $(p<0.001)$ [33]. However, that study measured IHL up to three years after initial CRF assessment and measured IHL using ultrasound, which is less accurate than ${ }^{1} \mathrm{H}-\mathrm{MRS}$. Similarly, another study reported low CRF was inversely associated with increasing MAFLD activity and steatohepatitis severity measured via liver biopsy [34], however, liver biopsies were conducted up to four months after CRF assessment. The results of the study reported herein, which showed that individuals with the lowest CRF had significantly higher IHL\% than those with the highest CRF, are in accordance with previous findings from an interventional study involving a mixed sample of adults with MAFLD and adults at risk of metabolic disease [35]. The results of the current study add to existing evidence, highlighting that even relatively small variations in CRF are associated with increased IHL in inactive adults with or at risk of T2D. Importantly, the assessment of CRF and IHL was undertaken within a narrow timeframe ( $<1$ week) and $\mathrm{IHL} \%$ was quantified using gold-standard ${ }^{1} \mathrm{H}-\mathrm{MRS}$ thus highlighting the novelty and methodological rigour of the present study.

There is strong evidence linking low CRF to insulin resistance. A recent meta-analysis of 8 cohort studies found that CRF was inversely associated with T2D prevalence independent of other risk factors such as BMI, TC, and family history of T2D [13]. Similarly, the results of this study showed that CRF was inversely associated with insulin resistance and other cardiometabolic risk factors such as systolic hypertension and inflammation. While participants with T2D had lower CRF than those without T2D, the difference was not statistically significant. Furthermore, as physical activity is inversely associated with IHL independent of BMI [36], only inactive participants were included in this study in an attempt to control for higher levels of physical activity - which incur cardioprotective benefits. Because of this, the mean level of CRF of participants was quite low at $21.5 \mathrm{~mL} / \mathrm{kg} / \mathrm{min}$. As reports show that CRF $<29.1 \mathrm{~mL} / \mathrm{kg} / \mathrm{min}$ increases the likelihood of developing metabolic syndrome six-fold [37], a greater number of participants with higher levels of CRF are required to provide more robust results.

While the mechanistic interplay between low CRF, MAFLD, and T2D remains unclear, it is purported that the incomplete oxidation of fatty acids in the mitochondria may contribute to the build-up of fatty acid by-products, such as ceramides and diacylglycerol

intracellularly, which impair insulin signalling pathways and mitochondrial function and may contribute to, or be the result of, low CRF [38, 39]. Importantly, T2D-related exercise intolerance appears to be reversed by structured exercise and is made evident by the amelioration of mitochondrial impairments, increased mitochondrial content, improved insulin sensitivity, decreased IHL and increased CRF [15, 16, 40, 41].

This study has limitations that should be considered when interpreting the results. Firstly, the results of this study, by nature, incorporated measures of CRF and $\mathrm{IHL}$ at a time-specific point and did not track the progression of any outcome to determine their relative importance in the development of MAFLD or T2D disease progression. Secondly, this study assessed the amount of $\mathrm{IHL} \%$ per se and the methodology employed cannot determine the amount of fibrosis or classification of more severe liver diseases such as non-alcoholic steatohepatitis and/or their association with CRF. Additionally, whilst ${ }^{1} \mathrm{H}$-MRS is currently considered the gold-standard non-invasive measurement technique for IHL\%, HOMA-IR is comparatively more limited and cannot provide inference into tissuespecific impairments in insulin sensitivity. Thirdly, although CRF was assessed using a validated graded exercise test model [31], the gold-standard of aerobic capacity testing is indirect calorimetry and where possible, this method should be utilised. Finally, while an attempt was made to control for high levels of physical activity by only recruiting individuals who reported to be inactive (exercising < 3 days/week), inter-participant variations in physical activity levels likely contributed to the associations between CRF and IHL.

\section{Conclusions:}

This study showed that CRF is inversely associated with ${ }^{1} \mathrm{H}$-MRS-quantified IHL in inactive adults with obesity. CRF is also positively associated with insulin resistance and other key cardiometabolic risk factors. Improving CRF should remain a key therapeutic target for the management of obesity-related disease. Further longitudinal studies are required to elucidate the relationship between CRF and the progression of obesity-related disease such as MAFLD and T2D.

\section{Abbreviations}

\section{CRF}

cardiorespiratory fitness

$\mathrm{IHL}$

intrahepatic lipid

${ }^{1} \mathrm{H}$-MRS

proton magnetic resonance spectroscopy

HOMA-IR

homeostatic model assessment of insulin resistance

T2D

type 2 diabetes

MAFLD

metabolic dysfunction-associated fatty liver disease

WC

waist circumference

SBP

systolic blood pressure

DBP

diastolic blood pressure 
FBG

fasting blood glucose

CRP

C-reactive protein

TC

total cholesterol

TG

total triglyceride

HDL

high density lipoprotein cholesterol

LDL

low-density lipoprotein cholesterol

ALT

alanine aminotransferase

AST

aspartate aminotransferase

RPE

rate of perceived exertion.

\section{Declarations}

\section{Ethics approval and consent to participate}

This study conformed to the ethical guidelines of the 1975 Declaration of Helsinki and the procedures were approved by The University of Sydney Human Research Ethics Committee. Eligible participants were screened via telephone interview and those whom met the inclusion criteria and provided written informed consent, were enrolled in the study and underwent assessments at The University of Sydney (NSW, Australia).

\section{Consent for publication}

Not applicable.

\section{Availability of data and material}

The datasets used and/or analysed during the current study are available from the corresponding author on reasonable request.

\section{Competing Interests}

The authors declare no conflict of interest relevant to this article.

\section{Funding}

This research was supported by funding from the Collaborative Research Network for Advancing Exercise \& Sports Science (CRN-AESS)/Research Capacity Building Seeding Grant Scheme and by funding from Diabetes Australia Research Trust. (Establishment Grant: N.A. Johnson). The funding bodies were not involved in the study design, data collection, data analysis and interpretation, or writing of the manuscript.

\section{Authors' contributions}

AS, SEK, and NAJ contributed to the design of the study. AS, SEK, KLW, and RNS collected the data. AS analysed and interpreted the data. AS drafted the manuscript. All authors critically appraised, read, and approved the final manuscript.

\section{Authors' Information}

\section{Affiliations}

1. NICM Health Research Institute, Western Sydney University, NSW, Australia

Angelo Sabag

2. Faculty of Medicine and Health, Discipline of Exercise and Sport Science, The University of Sydney, NSW, Australia

Angelo Sabag, Kimberley L Way, Rachelle N Sultana, Nathan A Johnson

3. The Boden Collaboration for Obesity, Nutrition, Exercise and Eating Disorders, The University of Sydney, NSW, Australia

Angelo Sabag, Kimberley L Way, Rachelle N Sultana, Nathan A Johnson 
4. Centre for Research on Exercise, Physical Activity and Health, School of Human Movement and Nutrition Sciences, The University of Queensland, QLD, Australia

Shelley E Keating

5. Exercise Physiology and Cardiovascular Health Lab, Division of Cardiac Prevention and Rehabilitation, University of Ottawa Heart Institute, Canada Kimberley L Way

6. Faculty of Medicine, University of Ottawa, Canada

Kimberley L Way

7. School of Health Sciences, Faculty of Health and Medicine, University of Newcastle, NSW, Australia Sean M Lanting

8. Central Clinical School, Sydney Medical School, Faculty of Medicine and Health, The University of Sydney, NSW, Australia

Stephen M Twigg.

Acknowledgements

Not applicable.

\section{References}

1. Wolf AM, Colditz GA. Current estimates of the economic cost of obesity in the United States. Obes Res. 1998;6(2):97-106.

2. Aronne LJ, Isoldi KK. Overweight and obesity: key components of cardiometabolic risk. Clin Cornerstone. 2007;8(3):29-37.

3. Snel M, Jonker JT, Schoones J, Lamb H, de Roos A, Pijl H, et al. Ectopic fat and insulin resistance: pathophysiology and effect of diet and lifestyle interventions. Int J Endocrinol. 2012;2012:983814.

4. Tilg H, Moschen AR, Roden M. NAFLD and diabetes mellitus. Nat Rev Gastroenterol Hepatol. 2017;14(1):32-42.

5. Younossi Z, Anstee QM, Marietti M, Hardy T, Henry L, Eslam M, et al. Global burden of NAFLD and NASH: trends, predictions, risk factors and prevention. Nat Rev Gastroenterol Hepatol. 2018;15(1):11-20.

6. Wahid A, Manek N, Nichols M, Kelly P, Foster C, Webster P, et al. Quantifying the Association Between Physical Activity and Cardiovascular Disease and Diabetes: A Systematic Review and Meta-Analysis. J Am Heart Assoc. 2016;5(9).

7. Lee IM, Shiroma EJ, Lobelo F, Puska P, Blair SN, Katzmarzyk PT, et al. Effect of physical inactivity on major non-communicable diseases worldwide: an analysis of burden of disease and life expectancy. Lancet. 2012;380(9838):219-29.

8. Church TS, Earnest CP, Skinner JS, Blair SN. Effects of different doses of physical activity on cardiorespiratory fitness among sedentary, overweight or obese postmenopausal women with elevated blood pressure: a randomized controlled trial. JAMA - Journal of the American Medical Association. 2007;297(19):2081-91.

9. Wahl MP, Scalzo RL, Regensteiner JG, Reusch JEB. Mechanisms of Aerobic Exercise Impairment in Diabetes: A Narrative Review. Front Endocrinol (Lausanne). 2018;9:181.

10. Canada JM, Abbate A, Collen R, Billingsley H, Buckley LF, Carbone S, et al. Relation of Hepatic Fibrosis in Nonalcoholic Fatty Liver Disease to Left Ventricular Diastolic Function and Exercise Tolerance. Am J Cardiol. 2019;123(3):466-73.

11. Kodama S, Saito K, Tanaka S, Maki M, Yachi Y, Asumi M, et al. Cardiorespiratory fitness as a quantitative predictor of all-cause mortality and cardiovascular events in healthy men and women: a meta-analysis. JAMA - Journal of the American Medical Association. 2009;301(19):2024-35.

12. Lee DC, Sui X, Church TS, Lee IM, Blair SN. Associations of cardiorespiratory fitness and obesity with risks of impaired fasting glucose and type 2 diabetes in men. Diabetes Care. 2009;32(2):257-62.

13. Wei M, Gibbons LW, Mitchell TL, Kampert JB, Lee CD, Blair SN. The association between cardiorespiratory fitness and impaired fasting glucose and type 2 diabetes mellitus in men. Ann Intern Med. 1999;130(2):89-96.

14. Forouhi NG, Misra A, Mohan V, Taylor R, Yancy W. Dietary and nutritional approaches for prevention and management of type 2 diabetes. Bmj. 2018;361:k2234.

15. Keating SE, Hackett DA, George J, Johnson NA. Exercise and non-alcoholic fatty liver disease: a systematic review and meta-analysis. J Hepatol. 2012;57(1):157-66.

16. Sabag A, Way KL, Keating SE, Sultana RN, O'Connor HT, Baker MK, et al. Exercise and ectopic fat in type 2 diabetes: A systematic review and metaanalysis. Diabetes Metab. 2017;43(3):195-210.

17. Sabag A, Way KL, Sultana RN, Keating SE, Gerofi JA, Chuter VH, et al. The Effect of a Novel Low-Volume Aerobic Exercise Intervention on Liver Fat in Type 2 Diabetes: A Randomized Controlled Trial. Diabetes Care. 2020;43(10):2371-8.

18. Croci I, Coombes JS, Bucher Sandbakk S, Keating SE, Nauman J, Macdonald GA, et al. Non-alcoholic fatty liver disease: Prevalence and all-cause mortality according to sedentary behaviour and cardiorespiratory fitness. The HUNT Study. Prog Cardiovasc Dis. 2019;62(2):127-34.

19. Shrank WH, Patrick AR, Brookhart MA. Healthy user and related biases in observational studies of preventive interventions: a primer for physicians. J Gen Intern Med. 2011;26(5):546-50. 
20. Schutte NM, Nederend I, Hudziak JJ, Bartels M, de Geus EJ. Twin-sibling study and meta-analysis on the heritability of maximal oxygen consumption. Physiol Genomics. 2016;48(3):210-9.

21. Bye A, Klevjer M, Ryeng E, Silva G, Moreira JBN, Stensvold D, et al. Identification of novel genetic variants associated with cardiorespiratory fitness. Prog Cardiovasc Dis. 2020.

22. Bouchard C, Daw EW, Rice T, Perusse L, Gagnon J, Province MA, et al. Familial resemblance for VO2max in the sedentary state: the HERITAGE family study. Med Sci Sports Exerc. 1998;30(2):252-8.

23. Matthews DR, Hosker JP, Rudenski AS, Naylor BA, Treacher DF, Turner RC. Homeostasis model assessment: insulin resistance and beta-cell function from fasting plasma glucose and insulin concentrations in man. Diabetologia. 1985;28(7):412-9.

24. Naressi A, Couturier C, Devos JM, Janssen M, Mangeat C, de Beer R, et al. Java-based graphical user interface for the MRUI quantitation package. MAGMA. 2001;12(2-3):141-52.

25. Stefan D, Cesare FD, Andrasescu A, Popa E, Lazariev A, Vescovo E, et al. Quantitation of magnetic resonance spectroscopy signals: the jMRUI software package. Meas Sci Technol. 2009;20(10):104035.

26. Gow ML, Baur LA, Johnson NA, Cowell CT, Garnett SP. Reversal of type 2 diabetes in youth who adhere to a very-low-energy diet: a pilot study. Diabetologia. 2017;60(3):406-15.

27. Fabbrini E, Sullivan S, Klein S. Obesity and nonalcoholic fatty liver disease: biochemical, metabolic, and clinical implications. Hepatology. 2010;51(2):679-89.

28. Kim G, Giannini C, Pierpont B, Feldstein AE, Santoro N, Kursawe R, et al. Longitudinal effects of MRI-measured hepatic steatosis on biomarkers of glucose homeostasis and hepatic apoptosis in obese youth. Diabetes Care. 2013;36(1):130-6.

29. Borg GA. Psychophysical bases of perceived exertion. Med Sci Sports Exerc. 1982;14(5):377-81.

30. Kuipers H, Verstappen FT, Keizer HA, Geurten P, van Kranenburg G. Variability of aerobic performance in the laboratory and its physiologic correlates. Int J Sports Med. 1985;6(4):197-201.

31. Hawley JA, Noakes TD. Peak power output predicts maximal oxygen uptake and performance time in trained cyclists. Eur J Appl Physiol Occup Physiol. 1992;65(1):79-83.

32. Younossi ZM, Golabi P, de Avila L, Paik JM, Srishord M, Fukui N, et al. The global epidemiology of NAFLD and NASH in patients with type 2 diabetes: A systematic review and meta-analysis. J Hepatol. 2019;71(4):793-801.

33. Palve KS, Pahkala K, Suomela E, Aatola H, Hulkkonen J, Juonala M, et al. Cardiorespiratory Fitness and Risk of Fatty Liver: The Young Finns Study. Med Sci Sports Exerc. 2017;49(9):1834-41.

34. Krasnoff JB, Painter PL, Wallace JP, Bass NM, Merriman RB. Health-related fitness and physical activity in patients with nonalcoholic fatty liver disease. Hepatology. 2008;47(4):1158-66.

35. Kantartzis K, Thamer C, Peter A, Machann J, Schick F, Schraml C, et al. High cardiorespiratory fitness is an independent predictor of the reduction in liver fat during a lifestyle intervention in non-alcoholic fatty liver disease. Gut. 2009;58(9):1281-8.

36. Kistler KD, Brunt EM, Clark JM, Diehl AM, Sallis JF, Schwimmer JB, et al. Physical activity recommendations, exercise intensity, and histological severity of nonalcoholic fatty liver disease. Am J Gastroenterol. 2011;106(3):460-8. quiz 9.

37. Lakka TA, Laaksonen DE, Lakka HM, Mannikko N, Niskanen LK, Rauramaa R, et al. Sedentary lifestyle, poor cardiorespiratory fitness, and the metabolic syndrome. Med Sci Sports Exerc. 2003;35(8):1279-86.

38. Chan Z, Ding C, Chooi YC, Choo J, Sadananthan SA, Sasikala S, et al. Ectopic fat and aerobic fitness are key determinants of glucose homeostasis in nonobese Asians. Eur J Clin Invest. 2019;49(5):e13079.

39. Nassir F, Ibdah JA. Role of mitochondria in nonalcoholic fatty liver disease. Int J Mol Sci. 2014;15(5):8713-42.

40. van Tienen FH, Praet SF, de Feyter HM, van den Broek NM, Lindsey PJ, Schoonderwoerd KG, et al. Physical activity is the key determinant of skeletal muscle mitochondrial function in type 2 diabetes. J Clin Endocrinol Metab. 2012;97(9):3261-9.

41. Sargeant JA, Gray LJ, Bodicoat DH, Willis SA, Stensel DJ, Nimmo MA, et al. The effect of exercise training on intrahepatic triglyceride and hepatic insulin sensitivity: a systematic review and meta-analysis. Obes Rev. 2018;19(10):1446-59.

\section{Figures}




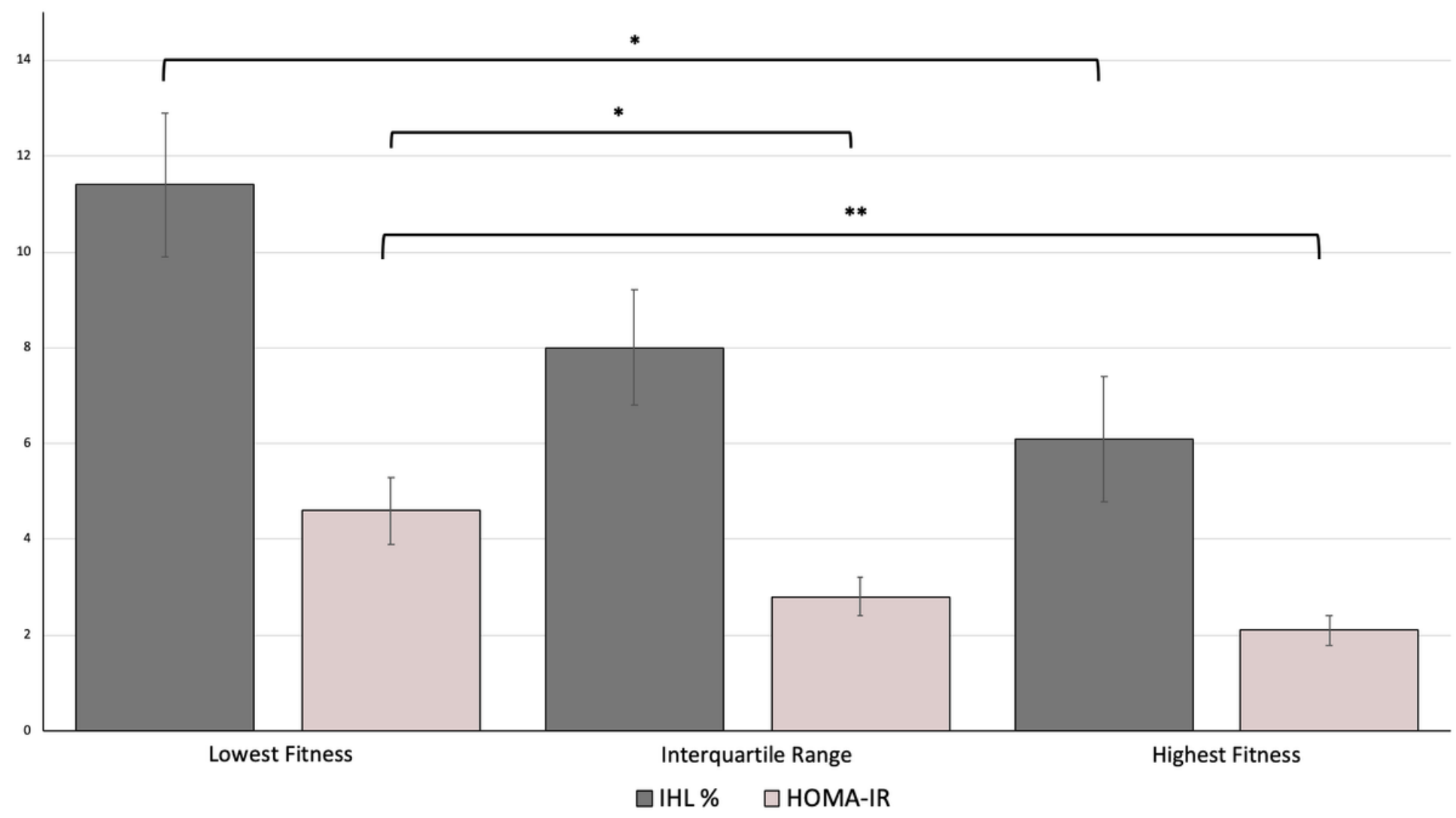

Figure 1

Differences in IHL\% and HOMA-IR between CRF quartiles. Differences in IHL\% between CRF quartiles. IHL\%, intrahepatic lipid \%; HOMA-IR, homeostatic model of insulin resistance. Brackets indicate significant difference. ${ }^{*}=p<0.05 ; * *=0.01$. 